\title{
Examination the Effect of Thermal Shock Test on SAC Solder Joints Fabricated by THRS and Multiwave Soldering Techniques
}

\author{
Daniel Koncz-Horvath $^{\mathbf{1}^{*}}$, Aliz Molnar ${ }^{\mathbf{2}}$, Greta Gergely ${ }^{1}$, Manoj Kumar Pal ${ }^{1}$ and Zoltan Gacsi ${ }^{1}$ \\ ${ }^{\prime}$ Institute of Physical Metallurgy, Metalforming and Nanotechnology, University of Miskolc, Miskolc, Hungary \\ FUX Corporation Hungary, Miskolc, Hungary
}

Received: 01 March 2018; accepted: 18 December 2018

\begin{abstract}
In this paper, the effect of soldering technique and thermal shock test were investigated on SAC 305 solder joints, produced by 2 different solder methods, which are the most common solder materials used for through-hole reflow soldering (THRS) and multiwave soldering techniques. The solder joints were subjected to different cycle numbers up to 5000 thermal shock tests with 2 different thermal profiles of $-30 /+110{ }^{\circ} \mathrm{C}$ and $-40 /+125{ }^{\circ} \mathrm{C}$. Microstructural properties of the tested joints were examined with the focus on intermetallic layer thickness and crack formation/ propagation. The thickness of the scallop-shaped $\mathrm{Cu}_{6} \mathrm{Sn}_{5}$ intermetallic layer was increased with increasing cycle number for both THRS and multiwave joints, but the thickening was more effective for the THRS joints. Cracks typically formed at the solder alloy-plated-through-hole (PTH) barrel and the solder alloy-pin interfaces and propagated along grain boundaries and precipitations of an intermetallic compound.
\end{abstract}

Keywords: SAC, thermal shock test, intermetallic layer, crack

\section{Introduction}

The quality performance and long-term reliability of electrical parts, units, devices and equipment are largely affected by operational conditions and service environment. For the reliability testing of solder interconnects used in commercial applications, reference test methods are specified by international standards and protocols. Thermal shock testing is performed to determine the ability of the tested product to consistently meet the criteria of a safe and reliable operation upon exposure to thermal shock. During thermal shock tests, thermo-mechanical loading conditions are created, thus accelerating early failure without reaching the upper temperature limit of the system.

Tanaka et al. [1] investigated tin-lead through-hole (THT) solder joints composed of a Pb-rich $\alpha$ phase and a Sn-rich $\beta$ phase. The studied solder joints were subjected to high temperature storage tests, temperature cycle tests, and thermal shock tests.

It was obvious from the high-temperature storage test results, that the roughness of the $\alpha$ phase progressed with longterm exposure to heat. Inspecting the cross-section of the fracture surfaces, cracks were mostly found to propagate along the micro-cracked $\alpha$ phase. The mechanism of cracking was described as follows: (a) thermal load promotes the coarsening of the $\alpha$ phase; (b) under repeated thermal cycling, increasing stress is applied to the solder joints - due to differences in the thermal expansion coefficient of the component pin and the plated copper layer (PCB); consequently, (c) the $\alpha$ phase undergoes elongation stretching in the direction of stress, which enhances (d) the occurrence of micro-cracks. Grain boundaries tend to roughen (in either phase) in response to stress; thus, the joining strength of the $\mathrm{Pb}-\mathrm{Sn}$ joint interface declines. This promotes (e) crack propagation along the grain boundaries, followed by the micro-cracking and final degradation of the $\alpha$ phase. Upon thermal shock testing, fractures occurred at sites where the solder adjoined the lead pin or the $\mathrm{Cu}$ pad. However, unlike in thermal cycling, no micro cracking of

\footnotetext{
*Author for correspondence: femkhd@uni-miskolc.hu
}

the $\alpha$ phase was observed. Heat stress caused by an abrupt temperature change during thermal shock testing promoted the coarsening and peeling of the $\alpha$ phase in the intermetallic compound layer. Ding et al. [2] studied the response of reflow- and wave-soldered $\mathrm{Sn}-\mathrm{Pb}$ solder joints to thermal fatigue testing ( 0 to 1200 cycles, $-55^{\circ} \mathrm{C}$ to $+125{ }^{\circ} \mathrm{C}$ temperature range, 15 min dwell time). It was found that cracks in the reflow-soldered joint propagated from the solder surface to the inner joint as a result of stress concentration deriving from the mismatch of various thermal expansion coefficients in the joint assembly. High stress rate due to thermal cycling occasionally caused plated-through-hole (PTH) barrel fracturing and plastic solder joint deformation. As emphasized by the authors, the geometry of the solder joint played an important role in affecting solder joint reliability. In wave-soldered joint specimens, the fillet shape notably influenced the stress releasing means, whereby some cracks got focused around the fillet surface (i.e., along the fillet lifting and at the corner of the $\mathrm{PCB}-$ component pin) rather than in the inner solder. Considering intermetallic compound (IMC) formation, it was shown that the $\mathrm{Cu}_{6} \mathrm{Sn}_{5}$ intermetallic layer is considerably thicker in reflow soldered joints than in the wave soldered samples. Three typical crack initiation sites were identified: (a) in the solder joint itself, due to plastic deformation caused by an abrupt temperature change during thermal fatigue testing; (b) at the solder-PTH interface, resulting from coefficient of thermal expansion (CTE) mismatch; and (c) at the component pin-solder interface, which was attributed to either the poor solderability of the pin or the brittleness of $\mathrm{Ni}-\mathrm{Sn}$ intermetallic layer (IML).

According to Restriction of Hazardous Substances (RoHS) and Waste Electrical and Electronic Equipment (WEEE) regulations, $\mathrm{Sn}-\mathrm{Pb}$ solder alloys were replaced with environmentfriendly, $\mathrm{Pb}$-free solder alloys. Similarly to $\mathrm{Sn}-\mathrm{Pb}$ alloys, the most commonly used $\mathrm{Sn}-\mathrm{Ag}-\mathrm{Cu}$ (SAC)-based alloys also suffer from failure due to thermal loadings. The failure mechanisms of SAC solder joints have been discussed by several studies [3-6]. It was observed that failure develops with crack propagation in the bulk material in the vicinity of interfacial regions $[7,8,9]$. The results of thermo-mechanical fatigue testing (fatigue life tests and thermal shock tests) largely 


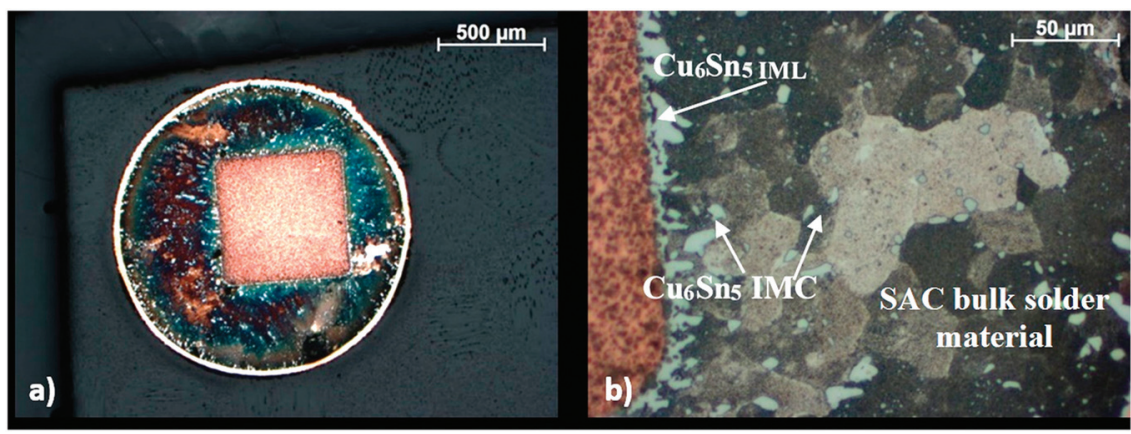

Figure 1. (a) Cross-section of the examined solder joint and (b) microstructure of the solder joint

depend on the microstructure of the solder [10, 11, 12, 13]. The mechanical properties of the bulk solder are obviously a function of as-solidified microstructure, yet the "destabilization" of this microstructure and the consequent recrystallization of the Sn phase due to thermal stress under thermal shock conditions pose considerable challenges to the reliability testing of solder joints [14]. Under the effect of high temperature during thermo-mechanical stress, high-density regions (i.e., regions of thermal stress concentration) undergo recrystallization, which leads to the nucleation and propagation of cracks along the recrystallized region. Recrystallization first evolves in strain concentrated areas then spreads through the bulk material, resulting in a crack profile representative of the heterogeneous microstructure $[15,16,17,18,19]$.

Besides recrystallization, the thick and brittle IML also plays an important role in the failure of SAC solder joints. It was shown by Sadiq et al. that the thickness of the IMC within the bulk solder alloy increases with increasing isothermal aging time [20]. As for ball grid array (BGA) joints, it was observed in ref. 21 that the IMC growth during thermal shock is more notable than that during thermal aging.

The aim of the present investigation is to follow the evolution of IML thickness and crack initiation/propagation during thermal shock tests of THT SAC solder joints produced by through hole reflow soldering and multiwave soldering. The microstructural characterization of SAC 305 is presented in our previous publication [22].

\section{Experimental}

Two sets of SAC 305 (provided by Henkel Ltd.) THT solder joints were produced. The first group was produced by through-hole reflow soldering (THRS), while the other one was fabricated by a multiwave soldering technique. Thermal cycling tests were carried out on the solder alloy with $30 \mathrm{~min}$ dwell time at temperature ranges of $-30 /+110{ }^{\circ} \mathrm{C}$ and $-40 /+125{ }^{\circ} \mathrm{C}$, after 500, 1500, 3000, 4000, and 5000 thermal cycles. The thermal loading method was preferred over thermal aging (annealing), because thermal cycle tests are the most common in the electronic industry. Scanning electron microscopy (Zeiss EVO MA 10 SEM), energy dispersive spectrometry (EDS), and image analysis were used. Optical microscopy was carried out with a Zeiss Imager M1m microscope and AxioVision Rel. 4.8 software. Sections were prepared perpendicular to the length of the pins to measure the IML thickness. The examined section and the microstructure are shown in Figure 1.

The sample preparation of test samples consisted of grinding $(320,500,800,2000,2400$, and $4000 \mathrm{SiC})$, polishing with $3 \mu \mathrm{m}$ MD MOL $+1-\mu \mathrm{m}$ diamond paste, and etching with $93 \mathrm{~mL}$ metanol $+2 \mathrm{~mL} \mathrm{HCl}+3 \mathrm{~mL}$ HNO3. The IML thickness was measured by selecting the IML area and dividing it by the length of the selected area using image analysis. The method of IML thickness measurement is shown in Figure 2.

\section{Results and Discussion}

Figure 3 shows a series of micrographs of THRS and multiwave solder joints subjected to thermal shock cycles with the $-30 /+110{ }^{\circ} \mathrm{C}$ thermal profile. Figure 4 shows a series of micrographs of THRS and multiwave solder joints subjected to thermal shock cycles with the $-40 /+125^{\circ} \mathrm{C}$ thermal profile.

In Figures 3-4, it can be seen that IMLs have a scallop shape for both THRS and multiwave techniques and both thermal profiles. The IMLs increase with increasing cycle number for both soldering techniques and thermal profiles. The top morphology (and shape) and the growth mechanism of IMCs were discussed by several researchers [23, 24].

Figure 5 shows the obtained IML thickness values versus thermal cycle diagrams for both THRS and multiwave samples and both thermal profiles. The initial IML thickness were $1.5 \mu \mathrm{m}$ at $-30 /+110{ }^{\circ} \mathrm{C}$ and $1.8 \mu \mathrm{m}$ at $-40 /+125{ }^{\circ} \mathrm{C}$ profile. Against the thermal cycle (5000 TW), the values increased [25], and the IML thickness was $8.1 \mu \mathrm{m}\left(-30 /+110{ }^{\circ} \mathrm{C}\right)$ and $7.6 \mu \mathrm{m}\left(-40 /+125{ }^{\circ} \mathrm{C}\right.$ profile $)$ in the THRS samples. However, thermal cycle test resulted in a slight increase of IML thickness in the multiwave sample, because the initial values

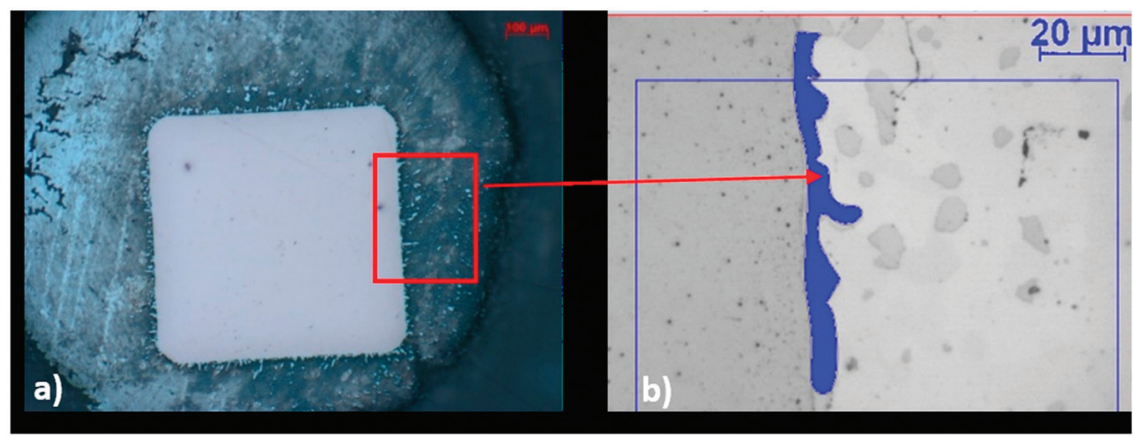

Figure 2. (a) Location of the IML thickness measurement of the examined solder joint and (b) the IML thickness measurement method 


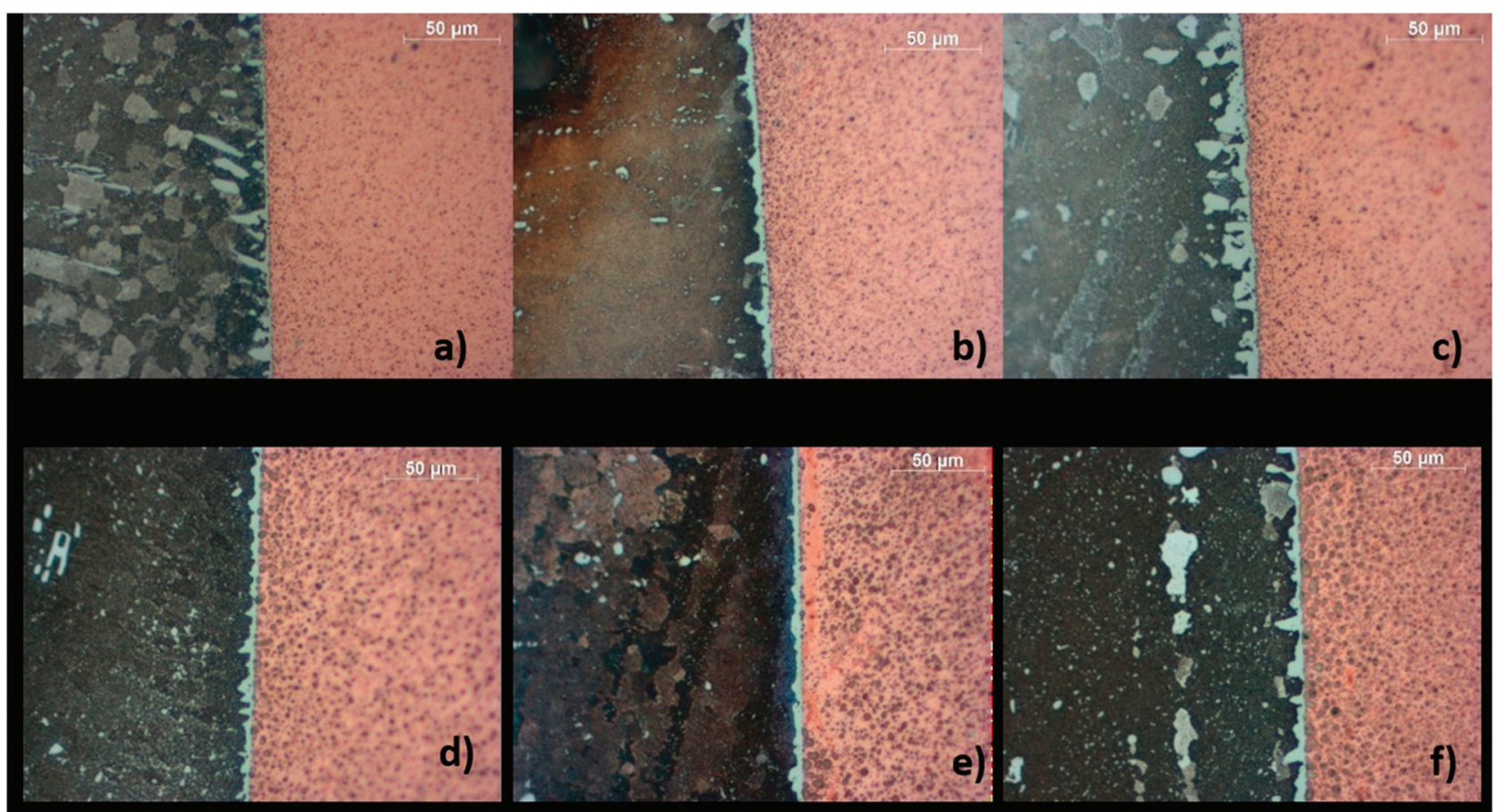

Figure 3. Micrographs of the IML of the samples subjected to thermal shock testing at $-30 /+110{ }^{\circ} \mathrm{C}$ : (a) SAC 405 THRS, 1500 cycles, (b) SAC 405 THRS, 3000 cycles, (c) SAC 405 THRS, 5000 cycles, (d) SAC 305 multiwave, 1500 cycles, (e) SAC 305 multiwave, 3000 cycles, and (f) SAC 305 multiwave, 5000 cycles

$1.3\left(-30 /+110{ }^{\circ} \mathrm{C}\right)$ and $1.4\left(-40 /+125{ }^{\circ} \mathrm{C}\right.$ profile $)$ were enhanced to $5.8 \mu \mathrm{m}\left(-30 /+110{ }^{\circ} \mathrm{C}\right)$ and $5.5 \mu \mathrm{m}\left(-40 /+125{ }^{\circ} \mathrm{C}\right.$ profile). It can be concluded that the interval of the thermal profile has low effect, because IML thickness values were nearly the same in both alloys. In low TW situation, IML thickness changed simultaneously in both alloys; however, in the case of 3000, 4000, and $5000 \mathrm{TW}$, the growth of IML layer was more severe in THRS samples, that is, the IML thickness grow was more pronounced for the THRS samples than for the multiwave samples. Multiwave soldering resulted in a lower IML thickness due its higher process speed [26]; thus, the number of Cu6Sn5 intermetallic compounds (IMC) is much higher in the multiwave samples than in the THRS samples. It can be the reason why the IML in the multiwave samples had a slight growth compared to the THRS samples in high TW situations.

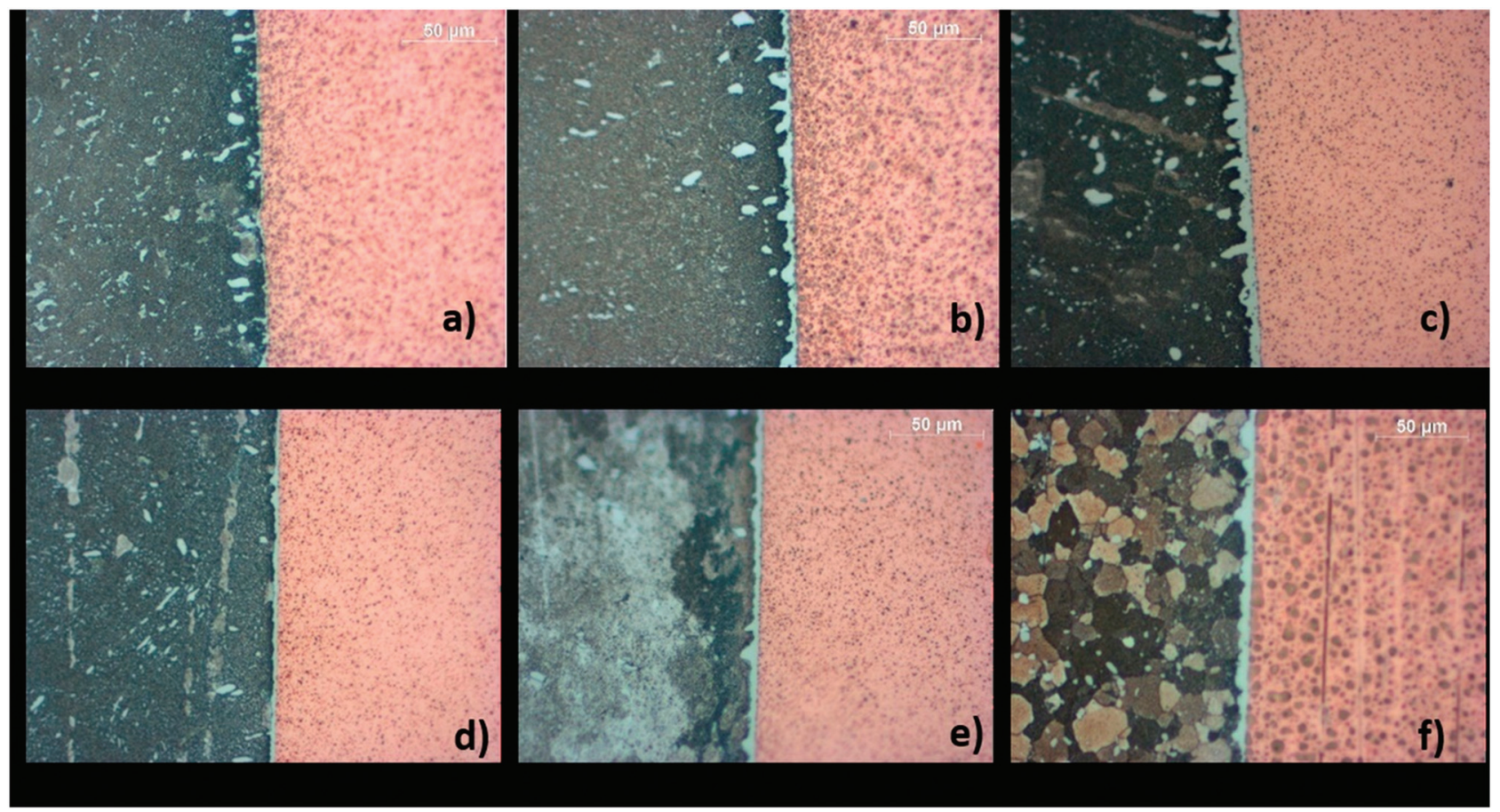

Figure 4. Micrographs of the IML of the samples subjected to thermal shock testing at $-40 /+125{ }^{\circ} \mathrm{C}$ : (a) SAC 405 THRS, 500 cycles, (b) SAC 405 THRS, 3000 cycles, (c) SAC 405 THRS, 4000 cycles, (d) SAC 305 multiwave, 500 cycles, (e) SAC 305 multiwave, 3000 cycles, and (f) SAC 305 multiwave, 4000 cycles 


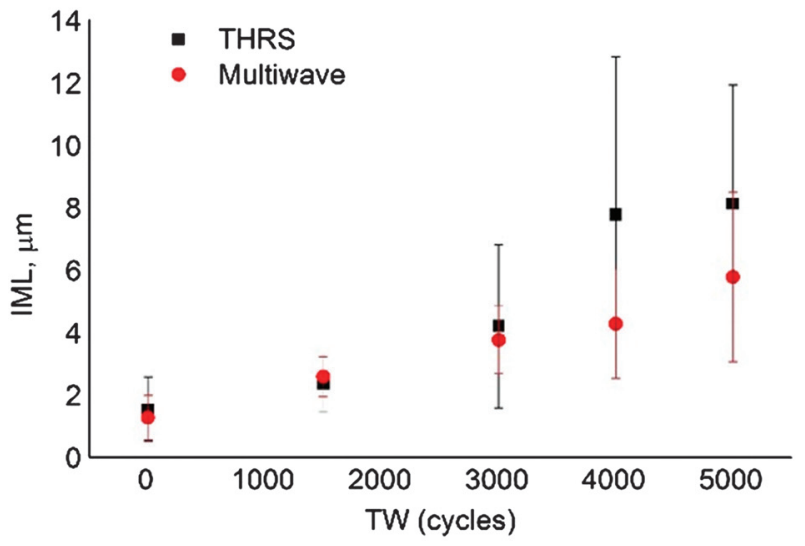

a)

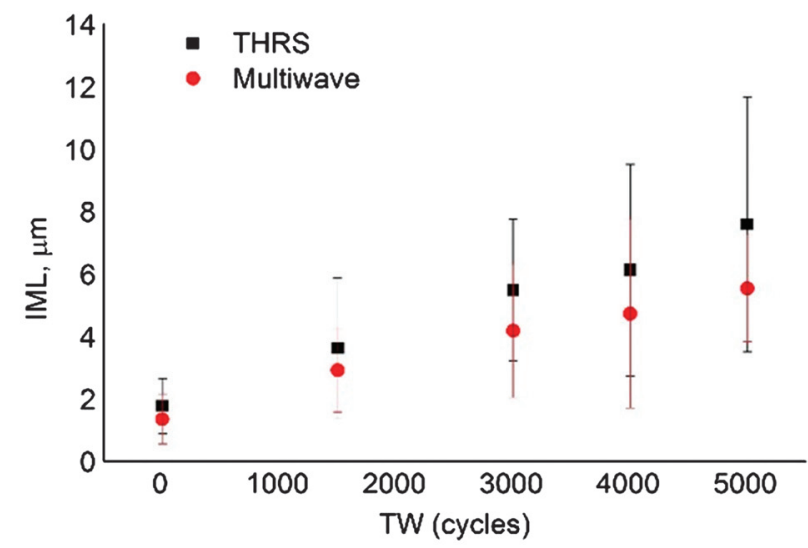

b)

Figure 5. IML thickness versus cycle number: (a) $-30 /+110{ }^{\circ} \mathrm{C}$ and (b) $-40 /+125{ }^{\circ} \mathrm{C}$ thermal profiles

Crack length versus cycle number is presented in Figure 6. The interval of the thermal profile had no significant effect on the crack length in any samples, that is, approximately the same crack length were measured in both type of samples at same TW, independently of the interval of the thermal profile. In the case of both thermal profiles, high TW resulted in more than twofold higher crack length in the multiwave samples than in the THRS samples.

The explanation for this phenomenon is due to the different soldering technologies and is related to the thickness of the layer. Lower IML was measured in the multiwave samples (approximately half) compared to that in the THRS samples

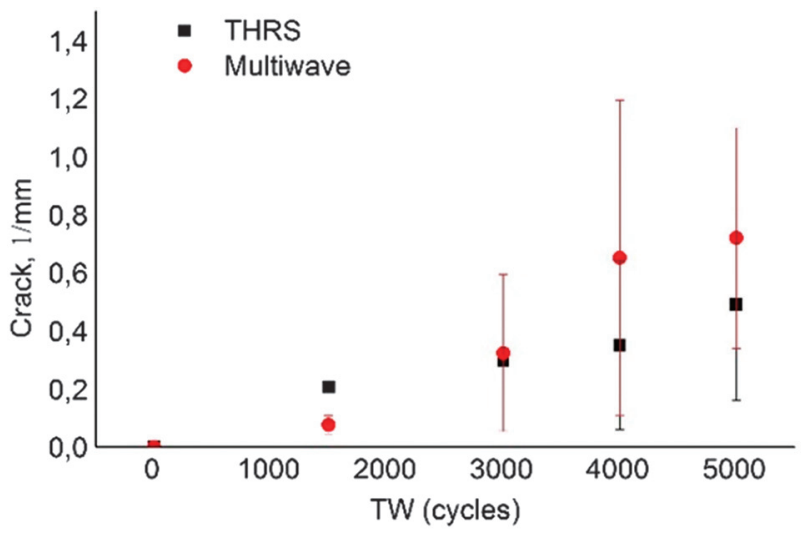

a)
(Figure 5) in high TW situation. Thus, the number of $\mathrm{Cu} 6 \mathrm{Sn} 5$ intermetallic compounds (IMC) is much higher in the multiwave samples than in the THRS samples. Due to thermal cycles, IMCs coarsen, and larger numbers of coarsened grains result in larger cracks.

Figures 7 and 8 show the SEM images, the EDS spectrum, and the measured point composition of the multiwave sample subjected to 500 cycles of the $-40 /+125{ }^{\circ} \mathrm{C}$ thermal profile. The crack formed in the solder fillet and propagated along the precipitation of the $\mathrm{Cu}_{6} \mathrm{Sn}_{5}$ phase (point 1).

SEM images and the elemental composition of the THRS sample in the case of 500 cycles of the $-40 /+125{ }^{\circ} \mathrm{C}$ thermal

Figure 6. Crack length versus cycle number: a) $-30 /+110{ }^{\circ} \mathrm{C}$ and (b) $-40 /+125{ }^{\circ} \mathrm{C}$ thermal profiles

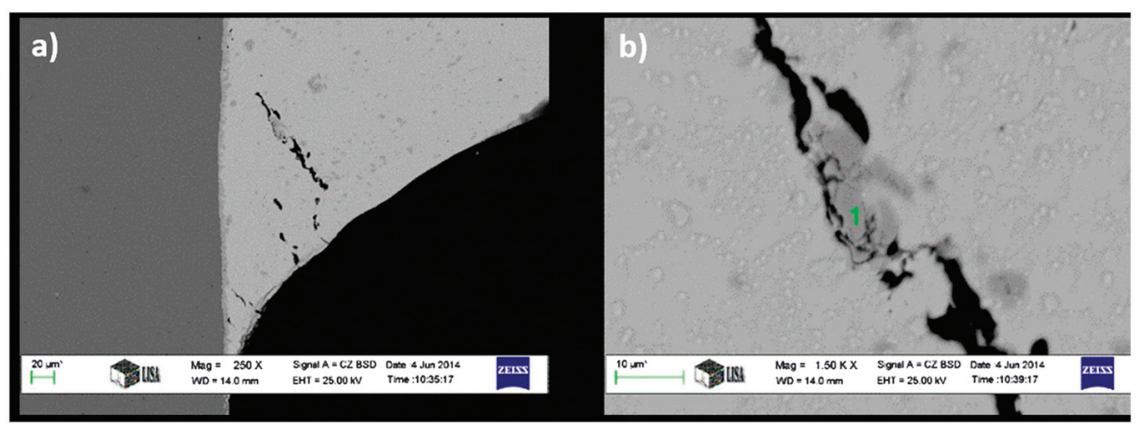

Figure 7. SEM micrographs of the SAC 305 multiwave sample subjected to 500 cycles of thermal shock with the $-40 /+125^{\circ} \mathrm{C}$ thermal profile: (a) crack in the fillet and (b) the crack with higher magnification 


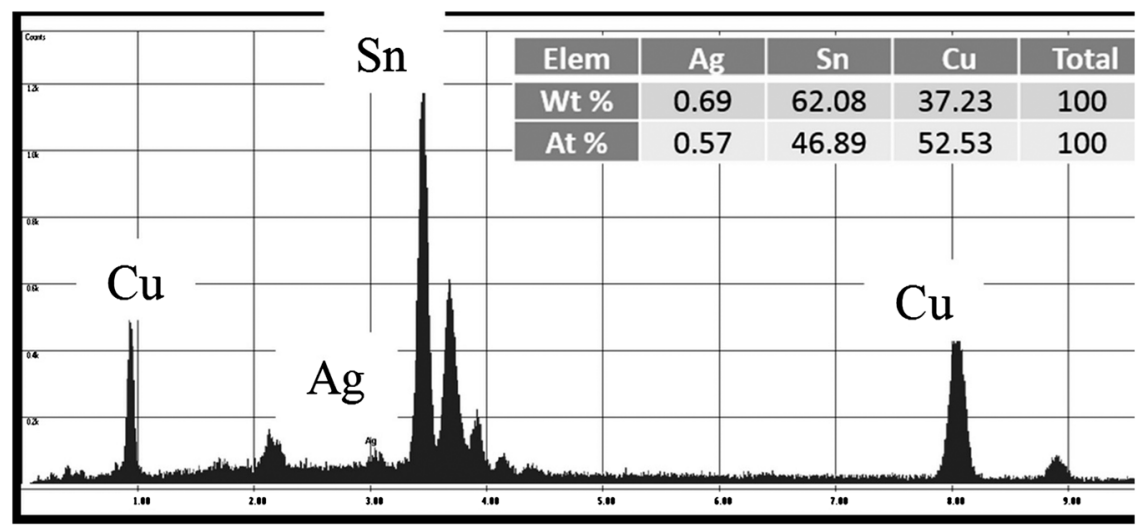

Figure 8. EDS spectrum and chemical composition of point 1 of the SAC 305 multiwave sample subjected to 500 cycles of thermal shock with the $-40 /+125{ }^{\circ} \mathrm{C}$ thermal profile

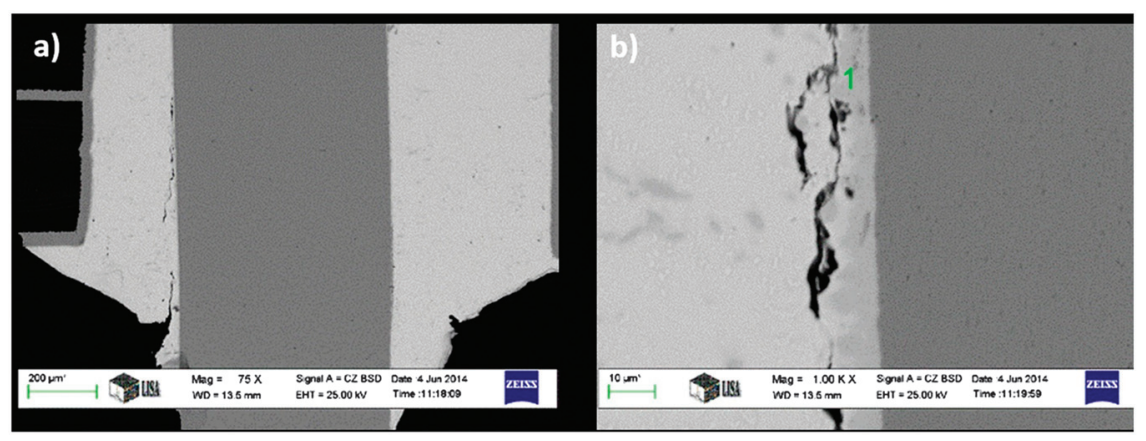

Figure 9. SEM micrographs of SAC 405 THRS sample subjected to 500 cycles of thermal shock with the $-40 /+125^{\circ} \mathrm{C}$ thermal profile: (a) crack near the pin-solder alloy interface and (b) the crack with higher magnification

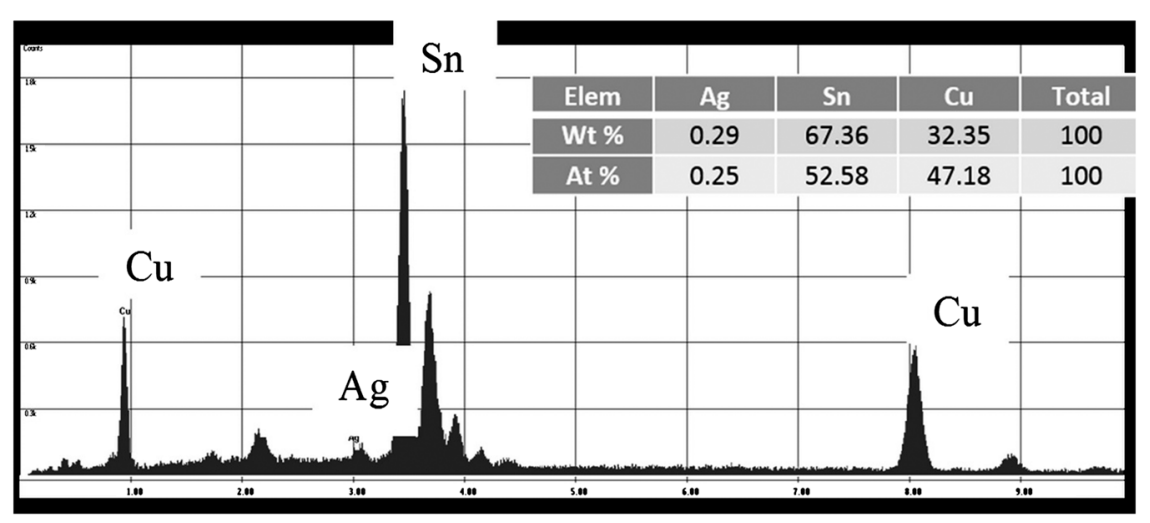

Figure 10. EDS spectrum and chemical composition of point 1 of the SAC 405 THRS sample subjected to 500 cycles of thermal shock with the $-40 /+125{ }^{\circ} \mathrm{C}$ thermal profile

profile are represented in Figures 9 and 10. The crack formed at the pin-solder alloy interface and propagated along the $\mathrm{Cu}_{6} \mathrm{Sn}_{5}$ phase (point 1).

SEM images show that the soldering defects - located primarily at the component pin-solder or solder-PTH barrel interface - are the most common initiation sites for fatigue crack propagation towards the inside of the solder joint. Propagation paths follow primarily the boundaries of intermetallic compound phases.

\section{Conclusions}

SAC solder joints produced by multiwave and THRS soldering techniques were subjected to different interval thermal shock tests. In this paper, the effect of the production method and the thermal profile were experimentally studied on the microstructure.

- The IML, formed at the pin-solder alloy interface, became thick with increasing thermal shock cycle in both types of joints. This phenomenon was more pronounced in joints produced by the THRS technique than that in the multiwave soldered joints. The thinner $\mathrm{Cu}_{6} \mathrm{Sn}_{5}$ thickness in the multiwave joint is probably due to the different process times of the techniques, i.e., less process time results in a thin IML layer and thus higher number of IMCs.

- Multiwave sample had twofold higher crack length than theTHRS samples, because the roughening of a higher number of IMCs resulted higher crack length. 
- Two typical crack initiation sites were identified in the samples. Cracks were located at the solder-PTH barrel interface in the multiwave samples - supposedly due to coefficient of thermal expansion (CTE) mismatch; while in the case of the THRS samples, cracks formed at the component pin-solder interface probably deriving from the soldering defects (void formation, pin hole, defective pin insertion, and poor hole fill). Crack propagation paths were either directed from the solder surface to the inner joint or proceeded intergranularly along Sn grain boundaries parallel to the solder joint, without penetrating the IMC phases.

- Applied thermal profile had no significant effect neither at IML thickness nor at crack length.

Acknowledgments. The research work presented in this paper was based on the results achieved within the GINOP2.3.2-15-2016-00027 and TAMOP-4.2.1.B-10/2/KONV-20100001 projects and was carried out as part of the TAMOP4.2.2.A-11/1/KONV-2012-0019 project in the framework of the New Szechenyi Plan. The realization of this project was supported by the European Union and was co-financed by the European Social Fund. The authors would also like to show their gratitude to the TERPLÁN Zénó Program supported by University of Miskolc.

Open Access. This is an open-access article distributed under the terms of the Creative Commons Attribution 4.0 International License (https://creativecommons.org/licenses/ by/4.0/), which permits unrestricted use, distribution, and reproduction in any medium, provided the original author and source are credited, a link to the CC License is provided, and changes - if any - are indicated. (SID_1)

\section{References}

1. Tanaka, H.; Aoki, Y.; Yamamoto, S. ESPEC Technology Report, No 3 1997, pp. 25-29.

2. Ding, Y.; Wang, C. Q.; Tian, Y. H. ICEPT Proc. 2003.

3. Frear, D. R.; Ramanathan, L. N.; Jang, J.-W.; Owens, N. L. Proc. 46th IEEE 2008, 450-454.

4. Lauro, P.; Kang, S. K.; Choi, W. K.; Shih, D. Y. J. Elect. Mat. 2003, 1432-1440. 5. Terashima, S.; Kobayashi, T.; Tanaka, M. Sci. Technol. Weld. Join. 2008, 732-738.

6. Mattila, T. T.; Mueller, M.; Paulasto-Krockel, M.; Wolter, K.-J. Proc. 3rd IEEE-ESTC 2010, 1-8

7. Stam, F. A.; Davitt, E. Microel. Reliab. 2001, 41, 1815-1822.

8. Collins, M. N.; Dalton, E.; Punch, J. J. Alloys Compd. 2016, 688, 164-170.

9. Hui, X.; Xiaoyan, L.; Yongchang, Y.; Na, L.; Yaowu, S. Rare Met. Mat. Eng. 2013, 42, 221-226.

10. Ding, Y.; Tian, R.; Wang, X.; Hang, C.; Yua, F.; Zhou, L.; Meng, X.; Tian, Y. Microel. Reliab. 2015, 55, 2396-2402.

11. de Vries, J. W. C.; Jansen, M. Y.; van Driel, W. D. Microel. Reliab. 2007, 47, 444-449.

12. Shnawah, D. A.; Sabri, M. F. M.; Badruddin, I. A. Microel. Reliab. 2012, 52, 90-99.

13. Sundelina, J. J.; Nurmi, S. T.; Lepisto, T. K.; Ristolainen, E. O. Mater. Sci. Eng., A 2006, 420, 55-62.

14. Snugovsky, L.; Snugovsky, P.; Perovic, P. P.; Rutter, J. W. Mater. Sci. Technol. 2005, 21, 61-68.

15. Laurila, T.; Mattila, T.; Vuorinen, V.; Karppinen, J.; Lia, J.; Sippola, M.; Kivilahti, J. K. Microelectron. Reliab. 2007, 47, 1135-1144.

16. Han, J.; Guo, F.; Liu, J. P. J. Alloys Compd., 2017, 704, 574-584.

17. Han, J.; Guo, F.; Liu, J. P. J. Alloys Compd., 2017, 698, 706-713.

18. Li, J.; Xu, H.; Mattila, T. T.; Kivilahti, J. K.; Laurila, T.; PaulastoKröckel, M. Comp. Mat. Sci. 2010, 50, 690-697.

19. Sundelina, J. J.; Nurmi, S. T.; Lepisto, T. K. Mater. Sci. Eng., A 2008, 474, 201-207.

20. Sadiq, M.; Pesci, R.; Cherkaoui, M. J. Electron. Mater. 2013, 42, 492-501. 21. Tian, Y.; Liu, X.; Chow, J.; Wu, Y. P.; Sitaraman, S. K. J. Electron. Mater. 2013, 42, 230-239.

22. Molnar, A.; Janovszky, D.; Kardos, I.; Molnar, I.; Gacsi, Z. J. Electron. Mater. 2015, 44, 3863-3871.

23. Yanghua, X.; Xiaoming, X.; Chuanyan, L. J. Mater. Sci. 2006, 41, 2359-2364.

24. Guohai, C.; Xiaoyan, L.; Jusheng, M. J. Electron. Mater. 2006, 35 , 1873-1878.

25. Shangguan, D. Lead-Free Solder Interconnect Reliability ASM International, 2005.

26. Schaefer, M.; Laub, W.; Sabee, J. M.; Fournelle, R. A.; Lee, P. S. J. Electron. Mater. 1996, 25, 992-1003. 